\title{
THE TREATMENT OF RESIDUAL EPIDEMIC ENCEPHALITIS.*
}

\author{
BY GEORGE H. HYSI,OP, New York. \\ I. INTRODUCTION. \\ II. Pathology. \\ III. Physiology. \\ IV. SYMPTOMs. \\ Interpretation of Symptoms. \\ V. The Therapectic Probicir. \\ Explanation of Table 1 . \\ VI. Summaries and Observatioxs. \\ VII. OBSERVATIONS ON Trhatient. \\ VIII. Conclusions.
}

\section{I.-INTRODUCTION.}

THE chronicity of the residual phenomena of epidemic encephalitis is a problem of therapeutic importance. The study here presented deals primarily with the treatment of Parkinsonian residua, which are exceedingly common. Grossman, ${ }^{1}$ in the re-examination of 89 cases of epidemic encephalitis, found that 58 per cent showed tremors or irregular involuntary movements; 50 per cent examined a year or more after recovery from the acute stage of the disease had these symptoms. This author estimates that approximately 10 per cent of his cases were becoming progressively worse. In the experience of the Neurological Service of Bellevue Hospital and of the Cornell Dispensary, the great majority of patients complaining of the after-effects of encephalitis present a Parkinsonian picture, with a vast variety of concomitant symptoms. Many of the patients are unable to earn as much as they could before their illness. Some cannot work at all through actual physical impediment. Nearly all have personality changes which often are in proportion to the physical symptoms and suggest that, although the disease does at times impair mentality without any evident physical symptoms, such impairments are due to the patient's reaction to his disability. In any event, these patients justly demand that medicine do what it can to relieve them. Inasmuch as encephalitis and its residua are new to medicine, we cannot make an accurate prognosis in the Parkinsonian cases. It is possible that the pathology of the discase makes complete recovery unlikely in the majority of cases. If so, amelioration of the symptoms is the best that can be done.

* From the Neurological Department, Bellevue Hospital, New York. 
The search for effective therapeutic measures compels, as a first step, consideration of the pathology of the disease, the functions of the tissues affected, and the symptoms occurring in the Parkinsonian picture.

\section{II.-PATHOLOGY.}

In the acute stages of the disease there occur cellular infiltration about the smaller vessels, varying degrees of degeneration of nervecells and fibres, and proliferation of neuroglia-cells. These processes are of greatest intensity in the grey matter of the basal ganglia, midbrain, and pons. The white matter is involved to a much less extent.

In the chronic stages there may be degenerative changes in the walls of the vessels, some perivascular infiltration (less in the more chronic cases), and pronounced neuroglia proliferation. I have not found reported any extensive observations as to changes in the various nuclei and their nerve-cells. There is scanty evidence of anything like a continued infection in most of these cases.

Inasmuch as in the acute stages the foci of greatest intensity are irregularly scattered, the chronic lesions will have a like distribution. In a given chronic case, for example, there may be lesions in the right basal ganglia, the hypothalamus, and the left posterior longitudinal bundle. These lesions will be where the foci of greatest intensity occurred in the acute stage. It is in this fashion that one can best account for the variety of concomitant symptoms present in a number of cases, all having two or three main symptoms in common.

Until we have studies of serial sections of the entire brain in cases of residual encephalitis, one may only guess at the true nature or extent of the pathological processes, and it will be impossible to understand accurately many of the symptoms, which are of great interest in that they throw light on the functions of the basal ganglia, diencephalon, mesencephalon, and pons.

\section{III.-PHYSIOLOGY.}

Various syndromes resulting from definite lesions of the basal ganglia, the diencephalon, and the mesencephalon are known. These structures have as their function the correlation of motor and sensory impulses to and from the cortex. Depending upon the site of a given lesion are the symptoms accompanying it. In addition to a correlative function, these parts of the brain have some influence in metabolism and in the function of the sympathetic nervous system. There are sympathetic cells in the mid-brain, and lesions of the mid-brain and hypothalamus often upset the vegetative nervous system. Leschke ${ }^{2}$ points out that alterations in function of the diencephalon, especially of the hypothalamus, may lead to important changes in the regetative 
economy, showing themselves in the form of diabetes insipidus, diabetes mellitus, dystrophia adiposogenitalis, heat regulatory changes, disturbances of pupillary reaction, and abnormalities of sweating and vasomotor activity. He states that in all cases of dystrophia adiposogenitalis lesions are found in the diencephalon, yet are often absent in the pituitary body. This is evidence of the existence of a metabolic centre in the diencephalon. Bing ${ }^{3}$ regards the salivation and hyperidrosis of encephalitis as due to diencephalon lesions.

The corpora striata have predominantly a motor function. Lesions here produce tonus and posture disorders, and also in some cases tremors of a certain type. The subthalamic and tectal regions also have a motor function.

The thalamus has a sensory function, and some authorities maintain that its state determines the feeling of well-being.

\section{IV.-SYMPTOMS.}

The outstanding symptoms in the Parkinsonian cases are rigidity, tremors of various types, and impairment of associated movements. Concomitant symptoms, which vary in the different cases, are numerous. Novel varieties constantly occur; but certain relatively common ones are worth mention-salivation, hyperidrosis (limited to the face in two cases, to one side of the body in two other instances), exophthalmos (stimulus of the grey commissure of the thalamus produces secretion of tears, dilatation of the pupils, and exophthalmos), ${ }^{4}$ strongly positive oculocardiac reflex, disturbance of the respiratory rhythm, and increase in weight. Two cases of diabetes insipidus and one of transient diabetes mellitus were observed. We found no instance of altered function of the sexual organs. Apropos of the salivation, it is sometimes found in paralysis, agitans, but in Parkinsonian encephalitis the salivation is intense and quite out of proportion to the other symptoms. The degree of salivation present is thus probably of diagnostic value in a case in which one cannot obtain a history of previous encephalitis.

Interpretation of Symptoms.-The symptoms may therefore be regarded as evidence of disturbance of the static system of motility ${ }^{5}$ and also the central ends of the vegetative nervous system. ${ }^{6}$ The basal ganglia and the diencephalon seem to be sites of the chief lesions. The nature of the morbid process is still a matter of question. It is still unknown whether the symptoms are due to persistence of the original infection, to a recrudescence, or are merely the result of a destruction of tissue during the acute stage of the disease. Bing holds that a definite pathology is established, and that the remaining syndrome is not due to the presence of the virus. 


\section{V. - THE THERAPEUTIC PROBLEM.}

Thus, the therapeutic problem in residual encephalitis is one of ameliorating symptoms due to degeneration in, or possibly to active infection of, certain tissues, with attendant impairment of function. General hygiene to maintain the body at its best level of activity is a first requisite. Re-educative measures to offset some of the motor disorders are important. Finally, drugs to counteract symptoms should be sought.

The chief symptoms to be treated by drugs are of two formsthose due to a disturbed static system of motility, and those evidencing a disturbance in the central ends of the vegetative nervous system. Both autonomic and sympathetic divisions are affected in residual encephalitis, and the problem is rendered the more difficult because of the fact that in a given patient the symptoms do not characterize disturbance of either part alone. There is rather a confusion of symptoms, showing that there is an irregular involvement of both divisions. The fluctuations in symptoms often made it difficult. to interpret the effects of drugs. Subjective changes and the influence of suggestion had to be considered. All patients but one of a group of fifteen encephalitics, the subjects of this study, were observed while they were on the ward. The period of observation averaged over a month for each case-for some patients as long as three months, and less than a month in only three instances.

Various drugs, including arsenic (both as Fowler solution and in the form of sodium cacodylate), strychnine, iron, urotropine, and the endocrine products were used in these and other post-encephalitics. Physiotherapy-massage, exercises, electrotherapy, and hydrotherapy - was given to nearly all cases. As other observers have learned, these methods of treatment seem to have no real curative effect.

In selecting drugs for experimentation, those having a definite action on the vegetative nervous system were chosen. Central depressants in particular seemed theoretically the most promising. The long-known value of hyoscine, a central depressant, in paralysis agitans, and the points of resemblance between that disease and the Parkinsonian residua of encephalitis, suggested the use of that drug. Other observers have found it helpful in residual encephalitis. Atropine and belladonna, although acting as central stimulants, were used. Belladonna preparations all contain some hyoscine, and therefore their action is difficult to interpret. Gelsemium and its active principle gelseminine are central depressants, and therefore demanded investigation. The action of this drug is not well understood, and it has not been used in residual encephalitis. In addition to these drugs, adrenalin, nicotine, picrotoxin, pilocarpine, and morphine were used, but chiefly as controls and to a less extent. Cicutine hydrobromate 
has been reported as of value. It has pharmacologically the same action as coniine, which in turn is similar to gelsemium. For that reason, and also because an opportunity did not present itself, no observations on cicutine were made.

Residual Encephaltis Casies.

\begin{tabular}{|c|c|c|c|c|c|c|}
\hline Cas? & $\operatorname{sex}$ & Age & $\begin{array}{l}\text { Interval from re- } \\
\text { covery fro:n acute } \\
\text { stage to onset cf } \\
\text { residual symp- } \\
\text { toms }\end{array}$ & $\begin{array}{c}\text { Period frum acits } \\
\text { stage to } \\
\text { admission to } \\
\text { hospital }\end{array}$ & $\begin{array}{c}\text { Period of } \\
\text { o'sservation }\end{array}$ & $\begin{array}{l}\text { Remarks as to residual } \\
\text { symptoms prior to } \\
\text { admission }\end{array}$ \\
\hline 1. I). 0. & $\mathbf{M}$ & 19 & None & $\begin{array}{l}\text { Admitted as } \\
\text { acute case }\end{array}$ & 4 months & Stationary \\
\hline 2. P. A. & MI & 18 & None & 12 months & 3 months & $\begin{array}{l}\text { Gradual progression } \\
\text { with remissions }\end{array}$ \\
\hline 3. J. C. & M & 30 & 2 months & 5 months & $2 \frac{1}{2}$ months & Stationary \\
\hline t. E. E. & MI & 17 & 1 month & $\tau$ months & $1 \frac{1}{2}$ months & Gradual progression \\
\hline 5. .J. 1). & $\mathbf{M}$ & 24 & 1 month & 12 months & 1 month & Gradual progression \\
\hline 6. H. В. & MI & 32 & inonths & 18 months & j weeks & Gradual progression \\
\hline T. J. W. & M & 56 & None & 16 months & 2 months & $\begin{array}{l}\text { Stationary } 1 \text { year, } \\
\text { relapse and pro- } \\
\text { gression for } \\
\text { months }\end{array}$ \\
\hline 8. P. B. & $\mathbf{F}$ & 28 & None & 14 montls & $\tau$ weeks & $\begin{array}{l}\text { Relapses at 3rd and } \\
9 \text { th months, sta- } \\
\text { tionary from then } \\
\text { on }\end{array}$ \\
\hline 9. II. S. & $\mathbf{F}$ & 26 & None & 20 months & 1 month & Stationary \\
\hline 10. E. 13. & $\mathbf{F}$ & 37 & None & $2+$ months & 6 weeks & Stationary \\
\hline 11. M. I.. & $\mathbf{M}$ & 19 & 14 months & 22 months & (6 weeks & Gradual progression \\
\hline 12. J. K. & $\mathbf{M}$ & 5.5 & 2 months & 26 months & j weeks & $\begin{array}{l}\text { Stationary, remis- } \\
\text { sions }\end{array}$ \\
\hline 13. S. F. & $\mathbf{F}$ & 14 & None & 18 months & 4 months & $\begin{array}{l}\text { Relapse 4th month, } \\
\text { gradual progression } \\
14 \text { months, with } \\
\text { slight remissions }\end{array}$ \\
\hline 14. P. W. & $\mathbf{M}$ & 30 & None & 16 months & 3 weeks & Stationary \\
\hline 1.5. S. .J. & $\mathbf{M}$ & 18 & 14 months & 18 months & 1 week & Gradual progression \\
\hline
\end{tabular}

The major part of the observations were upon the effects of hyoscine and gelsemium. As subjects there were 15 patients with residual symptoms of encephalitis. One patient had choreiform movements; the others were all of Parkinsonian type. One patient was under observation from the time of onset of the disease. The appended 
table gives the important details in each case. In addition to the post-encephalitics, 5 cases of trigeminal neuralgia were studied for the effects of gelsemium, and 3 paralysis agitans cases were studied for the effects of both gelsemium and hyoscine.

Explanation of Table I.-Of the 15 patients, 4 were female, 11 male. This proportion has held true in our experience of about forty cases of residual encephalitis. In all but two patients the residual symptoms were present from the time of the acute stages of the disease or within a short period after seeming recovery. In 2 instances there was an interval of normal health of fourteen months before new symptoms appeared. In both of these patients the Parkinsonian state developed gradually. Three of the fifteen patients had relapses; one patient (Case 7) had a relapse taking the form of bulbar palsy and seemingly had a recrudescence of the infection. In the other two instances (Cases 8 and 13) the relapse followed a miscarriage and a fall. In Case 3, after two months of nearly normal health, a fright occurred and Parkinsonian symptoms appeared at once. Emotional shock and strain are known frequently to be followed or accompanied by increase of symptoms in various organic diseases of the central nervous system. One may cite brain tumour, multiple sclerosis, cerebral forms of syphilis, paralysis agitans, and cerebral anteriosclerosis. Possibly emotional states produce cerebral circulatory alterations which, in the presence of disease, may further cripple functions already impaired.

\section{VI.-SUMMARIES AND OBSERVATIONS.}

Brief case summaries will be given first; observations of particular interest will follow; and finally the salient features of the various cases will be tabulated.

Case 1.-D. O., male, age 19.

History.-Onset February, 1921, Parkinsonian type; recovery by April 15. Residua stationary and consisting of slight physical symptoms and marked hypochondriasis. Discharged May 13.

Treatment.--Treatment of residua by hyoscine and gelsemium. No effects. After discharge took gelsemium for four months. No effects.

Case 2.-P. A., male, age 18.

History---Onset January, 1920. Partial recovery by February. Lethargy, weakness, and diplopia until July, when tremor, anteropulsion, and monotonous speech appeared. Gradual progression until admission, January, 1921. Discharged improved in February. Did well about one month, then got gradually worse again. Re-admitted April, discharged June 8.

Treatment.--During first admission improved under arsenic and physiotherapy. During second admission there were several fluctuations 
in symptoms, which seemed to be independent of medication. The greatest and most rapid improvement was when hyoscine was being given. Results are quite doubtful therefore.

Case 3.--J. C., male, age 30.

History.-Onset December, 1920 ; recovery in a month. Fright in Fcbruary, followed at once by tremor, stiff gait, monotonous voice, and stammering. Admitted May 3, discharged July 26, 1921.

Treatment.--Improved about 50 per cent, with occasional brief periods of slight relapse. Opium, given for four days, was accompanied by the most marked improvement. While taking gelsemium improvement was steady.

- Case 4.-E. E., male, age 17.

History.-Onset November, 1920 ; recovery for one month. Gradually progressive. Parkinsonian symptoms, commencing in January. Admitted July 1, 1921, marked Parkinsonian picture. Discharged Aug. 12.

Treatment.-Gelsemium only. There were slight fluctuations in condition, but in general a tendency toward progression. Drug not effective.

Case 5.-J. D., male, age 24.

History.-Onset June, 1920. One month later right-sided rigidity and tremor. August and September, diabetes mellitus. Parkinsonian features gradually progressed. Admitted July 19, discharged Aug. 22, 1921.

Treatment.-Gelsemium only. Steady and rapid improvement, practically well on discharge. Drug effective.

Case 6.-H. B., male, age 32.

History.-Onset January, 1920 ; recovery in two weeks. April, tremor left side of face, slowness in movement. Gradual increase of Parkinsonian features. Admitted July 29, discharged Sept. 15, 1921.

Treatment.-Improved steadily on gelsemium, got worse during ton days with arsenic, improved again as soon as gelseminine hydrochlorate was given. Discharged with at least 50 per cent improvement.

Case $7 .-\mathrm{J} . \mathrm{W}$., male, age 56.

History.-Onset January, 1920, followed by sommolence, rigidity left side, and slowness in all movements. January, 1921, had sore throat, dim vision, salivation, dysarthria, and dysphagia. Progressively worse. Admitted April 5, 1921, discharged Junc 10, 1921.

Treatment.-Made steady improvement on hyoscine and gelsemium. Relapsed on arsenic ; improved again while opium was given; worse under pituitary and adrenal extract. Hyoscine and gelsemium each partly effective.

Case 8.-P. B., female, age 28.

History.--Onset March, 1920, improred until July. Had a miscarriagc then, rapidly grew worse with Parkinsonian symptoms, with a severe relapse in January, 1921. Admitted May 20, discharged July 11, 1921. This patient was bedridden and absolutely helpless.

Treatment.-Steady and marked improvement under hyoscine and gelsemium, and under morphine. Made distinctly worse by atropine. In the last two weeks the patient received only urotropine and grew steadily worse. 
Case 9.-M. S., female, age 26.

History.-Onset March, 1920, followed by slight degree of Parkinsonian symptoms and marked diplopia. Patient very hypochondriacal. Admitted Nov. 7, discharged Dec. 2, 1921.

Treatment.-Rigidity slightly decreased by both gelsemium and hyoscine. Adrenalin followed by brief increase in rigidity, nicotine by brief decrease. Other symptoms unchanged.

Case 10.-E. B., female, age 37.

History.-Onset October, 1919, followed by moderate degrec of Parkinsonism, possibly a little worse the last six months. Admitted Oct. 16, discharged Nov. 28, 1921.

Treatment.-Improvement with hyoscine, gelsemium, and gelseminine hydrochlorate. All about equally effective. No improvement with opium. Adrenalin and nicotine had same effects as in Case 9.

Case 11.-M. L., male, age 19.

History.-Onset December 1919, with complete recovery in three weeks. Perfectly well until February, 1921. From then on, gradually progressive right-sided Parkinsonism. Admitted Oct. 10, discharged Nov. 28, 1921 .

Treatment.-Steady improvement under gelsemium, gelseminine hydrochlorate, and hyoscine, worse when none of these drugs were given. Adrenalin effects as in Cases 9 and 10.

Case 12.-J. K., male, age 55.

History.-Onset December, 1918, recovery in one month. In February, 1919, choreiform movement of the left leg, face, and shoulder appeared. This lasted three or four weeks ; since then there have been regular recurrences every six to eight weeks, not related to anything that the patient knows about. Admitted April 13, discharged May 11, 1921.

Treatment.-Improvement under gelsemium and hyoscine definite. Reported back to the hospital for three months after his discharge, and stated that as soon as he took gelsemium the movements decreased. Other drugs had no effect.

Case 13.-S. F., female, age 14.

History.-Onset January, 1920. Immediate left-sided Parkinsonian residua, but gradual improvement until August; then fell while skating and at once symptoms increased. After graduating from school in January, 1921, became steadily worse, the rigidity and tremor now being on the right side as well as the left. Admitted Nov. 18, 1921, discharged March, 1922.

Treatment.--Every time hyoscine, gelsemium, or gelseminine hydrochlorate was given there was distinct improvement. Atropine made her worse. Belladonna had no effect. Adrenalin increased rigidity. Picrotoxin, nicotine, and pilocarpine had no effects except for perhaps an hour or two after a dose was given; of these, nicotine decreased rigidity, the others increased it. The patient had four quite definite slumps in her condition, seemingly independent of what medication was being given. About 20 per cent improvement on discharge.

VOL. III.-No. 11. 
Case 14.-P. W., male, age 30.

History,-Onset February, 1920, followed by fatiguability, tremor, sweating, and slight left-sided Parkinsonism. Stationary. Admitted June 19, discharged July 9, 1921.

Treatment.-One week of gelsemium alone made definite objective betterment; addition of glandular substances and strychnine did not alter the rate of improvement. Results here are perhaps open to some question on the score of complex medication. However, the gelsemium started the improvement.

Case 15.-S. J., male, age 18.

History.-Onset March, 1920. Perfectly well until June, 1921. Sudden appearance of breathing irregularity, with paroxysms of deep and rapid breathing, accompanied by moderate degree of Parkinsonism. Gradual progression until admission Oct. 18, 1921. Discharged Oct. 24, 1921.

Treatment.-Parkinsonian symptoms immediately improved (some disappearing) under gelsemium. No change in respiratory phenomena.

In addition to the above 15 patients with residual encephalitis, gelsemium and gelseminine hydrochlorate were given to 3 paralysisagitans and 5 trigeminal-neuralgia patients. Two of the paralysisagitans patients were helped slightly by these drugs; one, an early case, was improved considerably. Four of the neuralgia patients were helped-one patient remarkably so-in that these drugs gave relief where morphine failed.

In the case summaries, it will be noticed that little mention has been made of the other drugs used, or of the physiotherapy given the patients. That is because of the fact that where favourable results were obtained they seemed to accompany the administration of the drugs hyoscine, gelsemium, or gelseminine hydrochlorate. Again, in residual cases not reported in this paper, where these drugs were not used, little or no relief was obtained. Moreover, space for detailed description of treatment and results would obscure the positive findings in the mass of negative findings.

\section{VII.-OBSERVATIONS ON TREATMENT.}

1. Adrenalin 1-1000, in doses of $20 \mathrm{~min}$. subcutaneously, increased the pulse-rate 50 per cent and definitely exaggerated the rigidity of the extremities for a period of two hours in three cases. Similar doses to non-encephalitic control cases had no such marked effects.

2. Nicotine sulphate, $\frac{1}{30} \mathrm{gr}$. subcutaneously, decreased the rigidity for a few minutes in three cases.

3. Picrotoxin, $\frac{?}{16} \mathrm{gr}$. orally three times a day, had no effect in one case. Given subcutaneously to the same patient, there seemed to be a temporary increase in rigidity.

4. Pilocarpine, $\frac{1}{1^{2}}$ gr. orally three times a day, had no effect on the one patient to whom it was given. 
5. Atropin, $\frac{1}{1} \delta$ gr. five times a day, made the patients worse in two instances (the same effects were noted in one other case not included in this report). Belladonna, as the tincture, in doses varying from 20 to 30 min. given three times a day, had no action, or produced cffects similar to those of atropine.

6. Morphine given as opium pills, 1 gr. twice a day, caused improvement during administration in three cases and produced no results in one case.

Of these drugs, those stimulating the central ends of the vegetative nervous system were followed by increase of Parkinsonian symptoms. Action on the peripheral ends of the autonomic seemed to be of slight importance. Morphine, as a central depressant, gave relief; but it is a drug that one could not well give continuously to a sufferer from residual encephalitis.

We now come to the effects of hyoscine, gelsemium, and gelseminine hydrochlorate. Hyoscine was used in doses of $\frac{1}{100}$ gr. three times a day (usually orally). The dose of gelsemium, in the form of fluid extract, was $7 \mathrm{~min}$. three times a day, although in some instances smaller doses were given. Gelseminine hydrochlorate was given in $\frac{1}{30}$-gr. doses three times a day, sometimes by mouth and sometimes subcutaneously; either mode of administration seemed to be equally effective.

Hyoscine was given to eight patients. Six (Cases 8, 9, 10, 11, 12, and 13) were definitely helped. Two (Cases 1 and 2) were not affected.

Gelsemium or gelseminine hydrochlorate, or both, were given to fifteen patients. Ten were helped (Cases 3, 5, 6, 7, 10, 11, 12, 13, $14,15)$; of these cases, 5, 6, 11, and 14 responded most noticeably. Two patients (Cases 8 and 9) should be classed as doubtful because of the slight and temporary improvement. Three patients were not helped at all (Cases 1, 2, and 4). With these drugs, cumulative symptoms, which consisted of heaviness of the eyelids, dim vision or diplopia, dizziness, and at times a feeling of languor or confusion, appeared in about one-third of the patients. When these symptoms appeared, reduction of the dose to 4 or $5 \mathrm{~min}$. thrice daily permitted continuous administration of the drugs. Cumulative effects disappeared within twenty-four hours after withdrawal of the drug, and were alarming in only one instance. That patient was one to whom gelsemium had been given for six days. She then received $\frac{1}{100}$ gr. of hyoscine subcutaneously. Within five minutes of the injection she developed all the symptoms of hyoscine poisoning, and for four hours was absolutely free of Parkinsonian symptoms. This patient had had hyoscine in the same dosage previously without any such effects. So the situation was repeated. The same symptoms recurred. These observations suggest a synergism between hyoscine and gelsemium. 


\section{VIII.-CONCLUSIONS.}

1. The Parkinsonian symptoms suggest overaction of the central ends of the vegetative nervous system.

2. Drugs depressing the central ends of the vegetative nervous system ameliorate, those stimulating increase, Parkinsonian symptoms.

3. Hyoscine produced objective improvement in 75 per cent of Parkinsonian cases. It reduced tremor and rigidity, restored mobility of facies, and enabled patients to walk and use the arms more freely.

4. Gelsemium and gelseminine hydrochlorate were effective in the same manner as hyoscine in 66 per cent and gave marked relief in 25 per cent of Parkinsonian cases.

5. Hyoscine gives more relief than gelsemium or gelseminine hydrochlorate in most instances where the three drugs are given; but since the latter two drugs have no dangerous side actions, they are preferable to hyoscine for prolonged administration.

6. Two patients seemed to be cured by gelsemium. The degree of relief cannot be predicted from the duration of symptoms prior to treatment, but is inversely proportionate to the severity of the symptoms. The duration of relief corresponds to the period of administration of treatment.

7. In continuing observations on dispensary patients it was occasionally found that while either one of the two drugs (hyoscine or gelsemium) would be of help, the other would be of no avail or might even increase the symptoms. This seldom occurred, and, since continuous and frequent observation of the patients was impossible, no explanation is offered for the seeming contrary action of the drugs.

8. While either hyoscine or gelsemium seems to be indicated in the treatment of Parkinsonian residua of encephalitis, and while these drugs usually proved beneficial as judged by objective improvement during their administration, it must be admitted that the therapeutic problem is not simple. These same drugs at times fail to help. Other drugs have been reported as giving striking relief in certain patients.

One of the most striking therapeutic results was observed by Dr. Kennedy ${ }^{7}$ in his private practice: "A woman of middle age who had been unable to articulate, chew, or move the arms or legs on volition-so intense was the Parkinsonian spasm-after a suppository of belladonna was able to talk fluently, move quickly and with grace, and express emotion easily by gesture and facial expression. Congealment of function gradually returned, but temporary dramatic amelioration has always been possible by the rectal use of belladonna in tolerance dosage".

More complete knowledge of the pathology, and of the function of parts affected by the disease, is necessary before we can predict what drugs should prove beneficial in a given instance. 
I wish to express my appreciation to Dr. Foster Kennedy, in whose service at Bellevue Hospital these patients were observed, for criticisms and suggestions during the course of this work.

\section{BIBLIOGRAPHY.}

Citations :-

1 Grossmax, M., “ Results in Epidemic Encephalitis “, Arch. of Neurol. and Psychiat., $\mathrm{v}, \mathbf{5 8 0}$.

2 Leschke, Deut. med. Woch., xlvi, 959 (Abs. Arch. of Neurol. and Psychiat., v, 311 ).

3 Bing, Schreiz. med. Woch., i, 4 (Abs. Arch. of Neurol. and Psychiat., v, 734).

4 Morat, Physiology of the Nervous System (Keener, 1906), 418.

"Hunt, J. Ramsay, "The Static and Kinetic Systems of Motility", Arch. of Neurol. and Psychiat., iv, 353.

6 Stewart, T. G., "The Vegetative Nervous System", Oxford Looseleaf System of Medicine, vi.

7 Kennedy, Davis, and Hyslop, Arch. of Neurol. and Psychiat., 1922, July, vii, 40. Other Sources:-

Brown, L., The Sympathetic Nervous System in Disease (Oxford Medical Publications, 1920).

Tilney and Rrley, Form and Functions of the Central Nertous System (Hoeber, 1921).

Wilson, S. A. K., “ Functions of the Basal Ganglia", Oxford Looseleaf System of Medicine, vi.

Cushny, Pharmacology and Therapeutics (5th ed., Lea and Febiger, 1910).

SAJous, Analytic Cyclopedia of Practical Medicine, vii (7th ed., Davis, 1916).

Epidemic Encephalitis : An Investigation by the Association for Research in Nervous and Mental Disease (Hoeber, 1921).

Abrahamson, "The Chronicity in Lethargic Encephalitis", Arch. of Neurol. and Psychiat., iv, 428.

Maggendorfen, Deut. Zeits. f. Nervenh., lxviii-lxix, 150.

Radovici and Nicolesco, Presse mid., xxix, 83.

Le Beries, Lyon méd., cxxx, 1032.

De Lrsi, Policlinico, xxviii, 505.

Cheinisse, Presse mód., xxix, 146. 